\title{
RECENT PROGRESS IN EMITTANCE CONTROL OF THE PHOTOELECTRON BEAM USING TRANSVERSE LASER SHAPE MODULATION AND TOMOGRAPHY TECHNIQUE*
}

\author{
M. Babzien, I. Ben-Zvi, R. Malone, X.-J. Wang, V. Yakimenko \\ NSLS, Brookhaven National Laboratory \\ Upton, New York 11973-5000 USA
}

March 1999

\author{
National Synchrotron Light Source \\ Brookhaven National Laboratory \\ Operated by \\ Brookhaven Science Associates \\ Upton, NY 11973
}

Under Contract with the United States Department of Energy
Contract Number DE-AC02-98CH10886

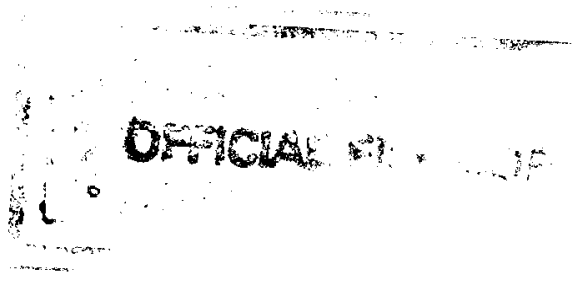




\section{DISCLAIMER}

This report was prepared as an account of work sponsored by an agency of the United States Government. Neither the United States Government nor any agency thereof, nor any of their employees, nor any of their contractors, subcontractors or their employees, makes any warranty, express or implied, or assumes any legal liability or responsibility for the accuracy, completeness, or any third party's use or the results of such use of any information, apparatus, product, or process disclosed, or represents that its use would not infringe privately owned rights. Reference herein to any specific commercial product, process, or service by trade name, trademark, manufacturer, or otherwise, does not necessarily constitute or imply its endorsement, recommendation, or favoring by the United States Government or any agency thereof or its contractors or subcontractors. The views and opinions of authors expressed herein do not necessarily state or reflect those of the United States Government or any agency thereof. 


\title{
RECENT PROGRESS IN EMITTANCE CONTROL OF THE PHOTOELECTRON BEAM USING TRANSVERSE LASER SHAPE MODULATION AND TOMOGRAPHY TECHNIQUE*
}

\author{
M. Babzien, I. Ben-Zvi, R. Malone, X.-J, Wang, V.Yakimenko,_BNL, Upton, NY 11973.
}

\begin{abstract}
A low emittance beam is very important for many applications, such as short-wavelength Free-Electron Lasers. A diagnostic that provides detailed information on the density distribution of the electron bunch in multidimensional phase-space is an essential tool for obtaining small emittance at a reasonable charge. Accurate phase space reconstruction and an analysis using a transport line with nine focusing magnets and techniques to control the optical functions and phases was demonstrated in previous publication. Relatively long time of measurements (approximately 30 minutes) was improved by installing Hall probes into each quadrupole magnet. This eliminated necessity to degauss all quadrupoles between each measurement points. Additional phase control of RF system and driving laser should also improve confidence in 5 dimensional phase space reconstruction.
\end{abstract}

\section{INTRODUCTION}

The determination of the electron beam density distribution in multi-dimensional phase-space is accomplished by the combination of two techniques: The slice-emittance measurement, which provides the longitudinal information, and transverse phase-space omographic measurement that provides the density distribution in the four transverse dimensions of phase space. Measurement of a slice emittance has been achieved and provided a clear demonstration of the linear longitudinal emittance-compensation scheme [1]. Changing the laser pulse profile of a photocathode RF gun has been suggested as one way to achieve non-linear emittance compensation [2]. The tomographic reconstruction of the phase space was suggested [3] and implemented $[4,5]$ using a single quadrupole scan. In the present work we give special attention to the accuracy of the phase space reconstruction and present an analysis using a transport line with nine focusing magnets and techniques to control the optical functions and phases. This high precision phase space tomography together with the ability to modify the radial charge distribution of the electron beam presents an opportunity to improve the emittance and apply non-linear radial emittance corrections.

\section{TOMOGRAPHIC RECOVERY}

Tomography is the technique of reconstructing an object from its projections. In the Physics of beams one can use tomographic techniques to reconstruct a beam density distribution in phase space using its projections in real space. In other words, the images of a beam on a phosphorescent screen (taken, for example, by a CCD camera) can be used to derive the phase-space densitydistribution. In order to do that, we must be able to rotate the distribution in phase space to generate independent projections on the screen. Changing the beam transport matrix, using variable strength lenses does this.

In order to establish the quality of the tomographic recovery procedure, a special program based on Mathcad was developed. Some of the issues studied were the tolerances for angular and stretching errors in the focusing channel, the required number of measured projections, the effect of smoothening during recovery and more. We concluded that in order to recover features that are about one tenth of the distribution size we should measure 32 evenly space projections and the rotation phase and stretch errors should be of the order of $10 \%$ or less.

\section{EXPERIMENTAL SETUP}

The schematic layout of the ATF acceleration and transport lines that were used in the slice emittance measurement and the tomographic reconstruction is presented in Figure 1.

In the naming convention of ATF elements, the first letter designated a particular straight beam line between bending dipoles, followed by letter(s) designating the type of element, followed by a number, increasing along the beam direction. Thus the $\mathbf{H}$ beam line (between the linac and the first dipole HD1) had quadrupole lenses HQ1 through HQ9, pop-up phosphor screen beam distribution monitors HPOP-UP 1 through HPOP-UP 2, etc. The beam is generated at the photocathode by a $10 \mathrm{ps}$ long UV laser pulse. A linear emittance compensation solenoid is located right after the RF gun controls the phase space distribution of the electron beam. Two RF linac sections with independent phase control accelerate 


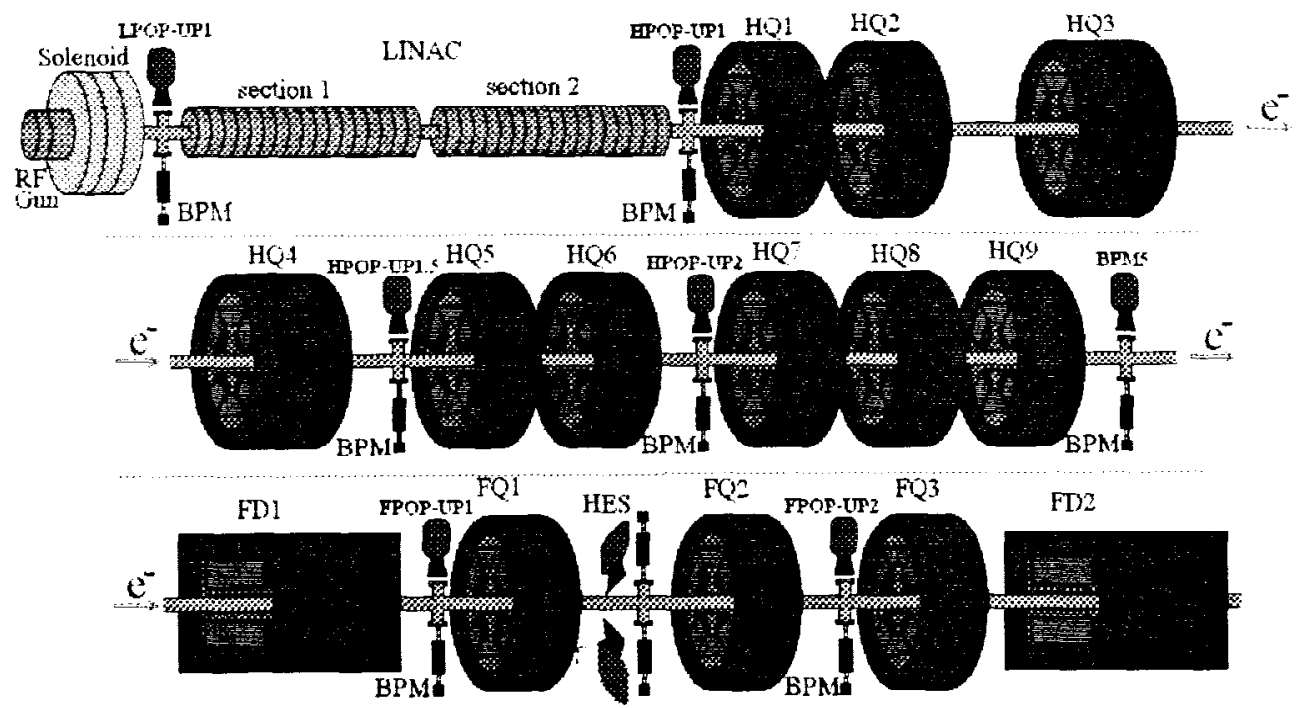

Figure 1. Schematic layout of the ATF accelerator system components used in the slice emittance measurement and the tomographic analysis.

beam from $5 \mathrm{MeV}$ to approximately $50 \mathrm{MeV}$. The phase of the second section is controlled independently by a motor controlled phase shifter. The $\mathrm{H}$ straight line with nine quadrupoles (HQl to HQ9) was used to generate rotations (phase advance) without a change in the beam size (constant optical functions). A beam profile monitor (BPM5) was used to measure the projection. The tomographic recovery procedure determines the phase space distribution at HPOP-UP1. The high energy beam is bent horizontally by a 20 degrees dipole magnet and a small slice in energy may be selected by a variable aperture slit. Additional beam diagnostics, located downstream of the slit provide charge and profile information.

\section{IMPLEMENTATION OF THE GAUSSMETERS}

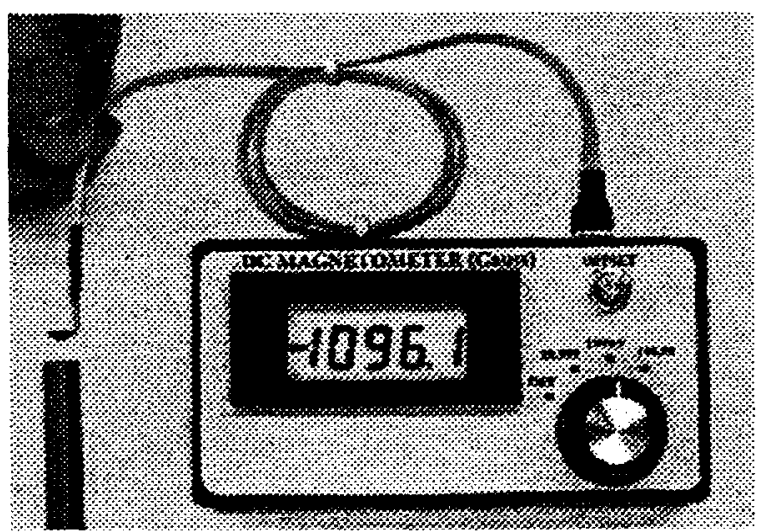

Figure 2. Photo of the DC gaussmeter.
DC gaussmeters were installed into each of the nine quadrupole magnets that we are using to control phase space rotation. This allows us set quadrupole current to desired value and measure actual gradient that effects the beam. Some problem occur during tests:

1. Noise from pulsed RF system was limiting the magnet field measurement accuracy. It was resolved by using rechargeable batteries to power hall probe.

2. The measured quadrupole field error was so far from calculated value that the resulting tune was unacceptable. The two solutions were used to address this issue: partial (fast) degaussing or second iteration for current setting.

3. The magnet power supplies noise limits accuracy of phase control. This problem is currently under investigation.

\section{MEASUREMENT PROCEDURE}

The tomographic measurement can be broken into a few steps [6].

1. The first step of the tomographic analysis is a measurement of the initial conditions of he electron beam at the linac's exit. The variation of the beam size as a function of current in the first triplet is used to match the optical functions in two directions. In the first step, the graphics window shows the beam size in the $X$ and $Y$ planes as a function of the triplet current. One can observe the fluctuations of the beam size and get a measure of the stability of the system.

2. In the second step, we calculate tunes for the justmeasured initial conditions of the beam. A simplex method is used to match the required phase advance and keep the electron-beam conditions at the end of the transport line nearly constant. At this stage, the graphical window shows the variation of the optical functions vs. position along the transport line for each selected value of the phase advance. 


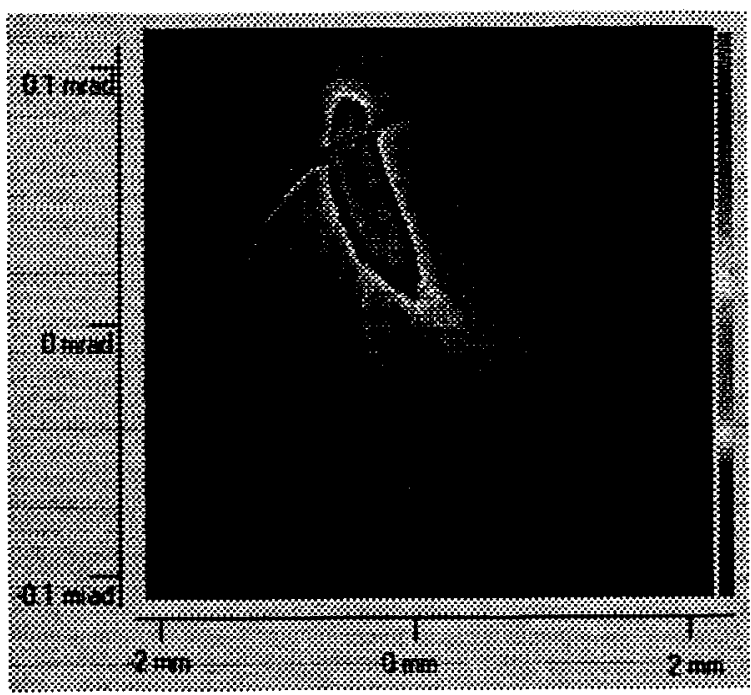

Figure 3. Tipical image of the recovered vertical phase space.

3. The third step is to measure the beam projections for the tumes calculated in the previous step. The graphics output window shows the measured projections in the $\mathrm{X}$ and $Y$ planes for a particular tune.

4. In the last step we reconstruct the phase space distribution from the measured projections. In this step the graphics window presents the recovered distribution in $\mathrm{X}$ $X$ ' and $Y-Y$ ' phase spaces.

The tomographic reconstruction of transverse phase space may be combined with the measurement of a longitudinal slice [1], to produce the transverse phase space distribution of a longitudinal slice [5]. This leads to a measurement of the $S$ dimensional phase space density distribution in $\left(X, P_{x}, Y, P_{y}, Z\right)$. For this purpose we replace the quadrupole scan emittance measurement by a tomographic analysis of the slice. Tomographic measurements of a slice may be done at FPOP-UP2 in the $\mathrm{Y}-\mathrm{Y}$ ' plane, or in one of the experiment hall beam lines downstream of another dipole (e.g. FD2), which are dispersion free.

\section{CONCLUSION}

As result of implementation of hall probes the data acquisition for phase space reconstruction was reduced from half of a hour to approximately 5 minutes. It is necessary to further reduce this time to be able reliably recover 5 dimensional phase space. Optimisation of the computer communication procedure can decrease measurement time in our case and will be addressed in near future.

\section{ACKNOWLEDGMENTS}

This work was supported by Department of Energy Contract DE-AC02-76CH00016

\section{REFERENCES}

[1] X. Qiu, K. Batchelor, L Ben-Zvi and X.J. Wang, Phys. Rev. Let. 76 No. $20,3723,(1990)$

[2] J.C. Gallardo, BNL Report 522246, (1990).

[3] J.S. Fraser, IEEE Trans. Nucl. Sci. NS-26, No. 1, 1641 (1979)

[4] C.B. McKee, P.G. O'Shea and J.M.J. Madey, Nucl. Inst. And Math. In Phys. Res. A358, 264 (1995)

[5] L Ben-Zvi, J.X. Qiu and X.J. Wang, Proceedings of the 1997 Particle Accelerator Conference, Vancouver BC Canada, May 12-16, 1997

[6] V. Yakimenko, M. Babzien, I. Ben-Zvi, R. Malone, and X.-J. Wang, Proceedings of the 1998 European Particle Accelerator Conference, Stockholm, Sweden, June 1998. 
